\title{
Can smoke control become smart?
}

\author{
Wojciech Węgrzyński ${ }^{1}$,* \\ ${ }^{1}$ Instytut Techniki Budowlanej, Zakład Badań Ogniowych, ul. Filtrowa 1, 00-611 Warsaw, Poland
}

\begin{abstract}
Smoke control solutions are used to maintain tenable conditions in buildings, enabling evacuation process, rescue operations and reducing the thermal stress on the building structure. For last 50-years the design process of such solutions did not significantly change - a required volumetric capacity is calculated with theoretical and empirical models, and further, mechanical design is prepared to deliver this capacity. In this paper, a new approach - "smart smoke control" is introduced, as a system that adapts the performance parameters based on the momentary measurements of temperature in the building. The system follows the growth and decay of fire in the building, which allows optimization of its mechanical parameters, and provides substantial increase in the performance. This paper provides a discussion on traditional and new concepts in smoke control, and defines areas, in which a paradigm shift must occur, to enable widespread adoption new and more efficient solutions. The paper does also refer to previous proof of concept studies, presenting the preliminary assessment of the performance of a smart smoke control system.
\end{abstract}

\section{Introduction}

Technical means to remove heat and smoke from buildings here referred to as "smoke control systems" or SHEVS, are essential equipment of large buildings. The need to manage the spread of smoke within the building is paramount to the provision of safety to the occupants. The role of such solutions in modern civil engineering development was described in [1].

The smoke control systems are designed to remove a certain amount of the mixture of air with hot gaseous products of combustion, referred to as "smoke". The amount of smoke depends primarily on the characteristics of the fire, but also on the architectural features of the building. This amount must be known to the designer, to dimension the technical solution for smoke removal. Thus, for last 50 years, a significant effort was taken to create analytical models of smoke flow in buildings, among many the most important studies are [2-6]. These methods typically quantify the fire in the form of prescribed "design fire", and further employ this assumption in theoretical and empirical models. The final result is the value of the mass flow of smoke in the thermal buoyant plumes in the building. The known value of the mass flow of smoke is then used to estimate the maximum temperature rise, and then finally a value of the volumetric flow of the smoke is given - this value will become the design goal for the further mechanical design of the smoke control system. This approach to the design is common for many standards and acts of law, and will be further referred to as "the traditional solution".

The aim of this paper is to present an approach different to abovementioned paradigm - a dynamic datadriven smoke control system employing real-time temperature measurements and smart algorithms to control the variable volumetric rate of the exhaust. This new solution will be further referred to as "smart smoke control". This solution was proposed for the first time in [7], which was also a proof of concept study, and a summary of all of the earlier work on development, implementation and modelling of such systems. A smart smoke control is a system that is dimensioned for the worst probable scenario of mass flow of smoke in a building, but able to adapt to changing density of removed smoke, thus being responsive to the growth and the decay of the fire within the building. This new approach allows for optimisation of the mechanical requirements for the system, including substantial savings on the shaft areas and energy supply.

\section{Goals of smoke control}

\subsection{Sources of knowledge}

\footnotetext{
* Corresponding author: w.wegrzynski@itb.pl
} 
Klote [8] following NFPA 92 [9] defines smoke control system as "an engineered system that includes all methods that can be used singly or in combination to modify smoke movement». These systems may be subdivided into two roles - (i) systems used to prevent people from coming into contact with the smoke, and (ii) systems that provide tenable conditions in the time necessary to leave the premise by its occupants.

Following BS 7346-4 [10], the SHEVS may serve as:

1) a means of protecting escape routes (keeping the escape and access routes free from smoke and radiant heat); or 2) a means of protection of property (protecting equipment and furnishings by reducing the damage caused by thermal decomposition products, hot gases and heat radiation); or

3) a means of controlling the temperature of hot, smoky gases affecting, for example, the building's structure, façades or glazing; or
4) a means of facilitating fire-fighting operations by creating a smoke-free layer; or

5) a combination of any of these.

In performance-based engineering [11] the requirements for the smoke control system are not predefined, and their place is taken by performance goals. In this approach to SHEVS design, the first pre-design is often verified as a "trial design", to demonstrate its ability to meet the design goals. In the past, a variety of tools was used for this purpose, including hand calculation models, zone models [12] or scale modelling. Today, the common approach is to use Computational Fluid Dynamics (CFD).

Once the verification of the smoke control performance is calculated, the overall safety of the design is usually quantified through the concept of Available and Required Safe Evacuation Times (ASET/RSET, [1]). In this concept, the tenability criteria within the building are expressed as a function of time and compared to the transient analysis of occupant evacuation.

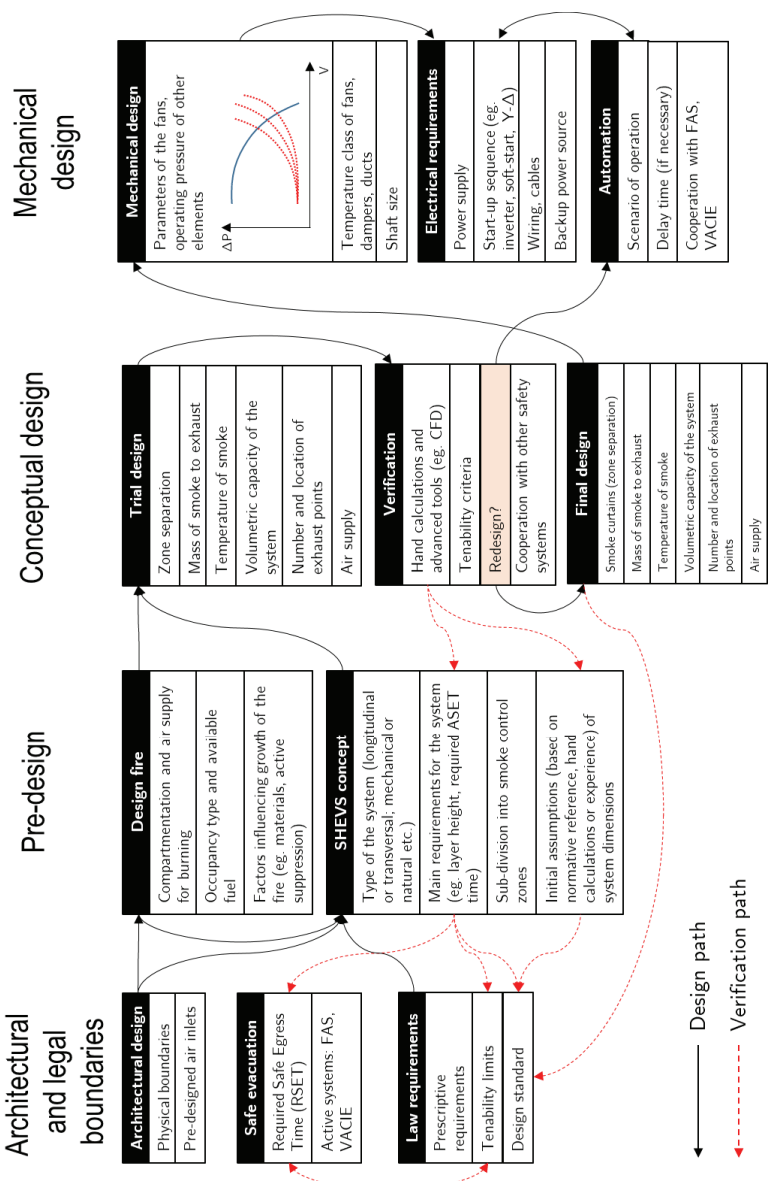

Fig. 1. The four major stages of the process of design of smoke and heat exhaust systems 


\subsection{The design process}

A SHEVS is designed for a given architecture and occupancy of a building - either newly designed or existing, which can be considered as the first boundary of the design. The design fire, which also depends on the architecture and the occupation type of the compartment, is determined by fire safety engineer, however, from the point of view of the smoke control designer, it is also a prescribed, rigid boundary. The design of a smoke exhaust system can be subdivided into three stages: (i) pre-design, (ii) conceptual and (iii) mechanical stage. In the pre-design and conceptual stages, the work is carried either by fire safety engineers or civil engineers, following requirements of the law, standards and guidebooks. In pre-design phase, the type of the solution, the primary goals of system operation and preliminary subdivision of the building into smoke control zones is chosen. In conceptual phase, the basic parameters of systems are determined: the mass flow of air (smoke) to be exhausted, the temperature of the smoke, number and location of exhaust points, air supply strategy, the scenario of operation, cooperation with other safety features of the building etc.

The conceptual project is then translated into a mechanical project (MEP). The temperature of smoke becomes the temperature rating of the fans, dampers and ducts; mass flow is translated into the volumetric capacity of fans, and the operating point of the whole system is calculated to define the pressure drop. With this knowledge, the area of ducts, sizing of dampers and vanes can be chosen, cope the requirements of the project, fit into the architecture of the building and meet the capabilities of devices available at the market. For the exhaust fan to work, its electrical characteristic must be known to dimension the power supply, as well as the startup power and strategy.

The whole design process, compressed into a single scheme, is presented in Figure 1. It must be noted, that critical part of the design happens before (definition of the architectural and legal bounds) and after (MEP design) the main part of the smoke exhaust system design. Available guidelines for smoke control system design scarcely explain these essential parts of the process, and this work is usually performed by parties not educated in fire safety engineering (e.g. architects, structural engineers and MEP engineers). Yet, the consequences of these design periods are significant for the cost and the final performance of smoke control system.

\section{Sensor-driven smoke control}

The new solution of smart smoke control does benefit from reducing the unnecessary margins of performance introduced into the design during the final MEP design process. In this phase, all critical parameters of the system infrastructure are determined in this phase for maximum underpressure at ambient temperature. However, this pressure in fire operation will be significantly lower $[7,13]$. The system adapting to the momentary density of smoke can benefit from reduced friction due to lower density, which allows higher airflow velocities in shafts and ducts. This also relaxes the requirements for the fresh air supply, as it is continuously delivered at ambient air density. These factors were the initial assumptions for the development of the smart smoke control concept presented herein.

Compared to traditional systems, the smart smoke control system must be equipped with additional components, mainly:

1. An exhaust fan that is capable of working at high volumetric capacity supplied through a frequency inverter;

2. Sensor array - e.g. temperature, pressure or motor power measurements, that will allow determination of the density of the smoke;

3. Control panel that is able to process the data received by the sensor array (2) and can alter the frequency of power supplied to the motor (1), thus changing its rotational speed and volumetric capacity.

The idea of the smart smoke control system is shown in Fig. 2. The solution of the exhaust fan, sensors and automation may be a complete solution "in a box" with the exhaust fan, or individual system developed in the building.

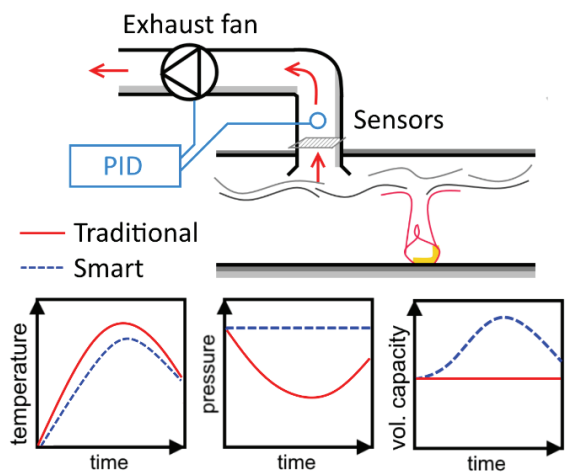

Fig. 2. The concept of the smart smoke control system

The benefit of smart smoke control solution results from the difference in mass flow rate exhausted by the fan, at ambient and maximum temperature. The minimum volumetric capacity of the smart smoke control system is determined by calculation of the maximum mass flow of smoke to be removed from the compartment, and the ambient air density. An example, employing most basic thermal plume correlation [14], is shown in Eq. $1-2$.

$$
\begin{gathered}
\dot{m}_{p}=C_{e} P Y^{3 / 2} \\
\dot{V}_{\text {min }}=\frac{\dot{m}_{p}}{\rho_{a m b}}
\end{gathered}
$$

where: $m_{p^{-}}$mass flow in thermal plume $[\mathrm{kg} / \mathrm{s}], C_{e}-$ empirical configuration coefficient, $P$ - circumference of the fire source $[\mathrm{m}], Y-$ height of the plume $[\mathrm{m}], V_{\min }-$ minimum volumetric flow capacity of system in ambient conditions $\left[\mathrm{m}^{3} / \mathrm{s}\right], \rho_{a m b}$ - ambient air density $\left[\mathrm{kg} / \mathrm{m}^{3}\right]$. 
This is the volumetric capacity, for which all of the MEP design should be carried, with the exception of the choice of the maximum volumetric capacity of the exhaust fan

As the temperature of the smoke rises during a fire event, the density of the smoke will decrease. In traditional solution, this is just an expected side-effect of system performance; however, in the smart smoke control concept, this is the physical phenomenon that allows for the increase of system performance. In smart smoke control, the volumetric capacity of the exhaust fan is increased, in order to maintain constant mass flow rate (Eq. 1) of the system. The maximum volumetric flow rate of the fan should be obtained at the maximum design heat release rate point of the fire (HRR) and can be determined with Eq. $3-4$. This is the value, for which the exhaust fan should be designed.

$$
\begin{gathered}
\theta=\frac{\dot{Q}_{c o n v}}{\dot{m}_{p} c_{p}} \\
\dot{V}=\frac{\dot{m}_{p}}{\rho_{a m b}}\left(\frac{T_{a m b}+\Theta}{T_{a m b}}\right)
\end{gathered}
$$

where: $\Theta$ - rise of the temperature of smoke in fire [K], $\mathrm{T}_{\mathrm{amb}}$ - ambient smoke temperature $[\mathrm{K}], Q_{c o n v}{ }^{-}$convective part of the fire heat release rate of the design fire $[\mathrm{kW}], c_{p}$ - specific heat of air $[\mathrm{kJ} / \mathrm{kg}], V_{\max }$ - maximum volumetric flow capacity of system in maximum temperature $\left[\mathrm{m}^{3} / \mathrm{s}\right]$,

As an example, the change of mass flow rate through an exhaust point with constant volumetric capacity of $10 \mathrm{~m}^{3} / \mathrm{s}$, following the change of temperature is shown in Fig. 3.

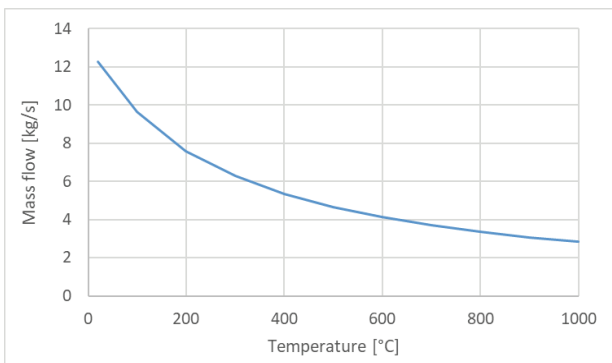

Fig. 3. Change of mass flow rate at exhaust point with capacity of $10 \mathrm{~m}^{3} / \mathrm{s}$ in function of temperature

It is assumed, that smart smoke control system fan will work at limited rotational speed (power supply frequency) in normal (ambient air) operation mode, to provide the volumetric flow determined by Eq. 2 . At the maximum rotational speed (often at a frequency of $50 \mathrm{~Hz}$ or $60 \mathrm{~Hz}$ ) the fan should provide maximum volumetric capacity, Eq. 4. It must be noted, that at higher temperature there will be additional effects:

- the pressure curve of the fan will change in different air density;

- the impeller blades will expand due to thermal effects, which may change the gap between impeller and frame, thus slightly increasing the fan capacity;
- the change of volumetric capacity may be smaller than resulting from the change of air density (Fig. 3), due to additional effects related to increased friction in moving parts of the motor, which will result in the change of required motor power that does not linearly follow the change of the temperature.

These effects will require further experimental confirmation. At the time being, based on the observations during high-temperature tests of exhaust fans [7], their combined effect is considered smaller than the increase of the system performance resulting from the change in rotational speed.

\section{Benefits of smart smoke control}

\subsection{Numerical verification}

The complex effects of feedback-loop between smoke exhaust capacity, the size of the fire and the temperature of removed smoke, is difficult to capture in the simple mathematical framework. However, such effects may be thoroughly investigated with more advanced methods, such as Computational Fluid Dynamics (CFD). To be able to capture the performance of smart smoke control in a CFD analysis, it is necessary to implement a new boundary condition type for the exhaust point, which can change its momentary exhaust rate, based on the temperature measurements at a chosen point of the model. This is possible in solvers such as ANSYS Fluent $\mathbb{R}[15]$, through the concept of User Defined Functions (UDF's). UDF's are user-generated scripts, written in C language, that may be executed by the solver at any particular point of the simulation. Their execution may cause different actions: e.g. writing and processing data, changing the boundary conditions in the model. In this case, the UDF was created to carry out following procedure at the end of each discrete time step:

1. Measure the temperature at a chosen point of the domain, e.g. as an average temperature at the boundary condition, or in a point located $1 \mathrm{~m}$ upstream of the exhaust fan;

2. Calculate average temperature of exhausted gasses from last 10 iterative time step (moving average);

3. Calculate the new volumetric capacity of exhaust fan following prescribed function of $V=f(T)$;

4. Change the volumetric capacity of "VELOCITY INLET" boundary conditions that represent the fan, and return to the solver.

It is necessary to mention, that in this case the boundary condition modified by the UDF is "velocity inlet", which defines the components and the scalar quantitates that are used to compute inlet mass flow rate, momentum fluxes, as well as fluxes of energy. The pressure drop at the boundary condition is a result of the calculation, and as such it does not affect the flow through the fan. In a real case, the pressure drop at the fan will influence its operating point, and other parameters, such as required shaft power. A more realistic representation of this boundary condition would be with one of the advanced fan models that are available in ANSYS Fluent ${ }^{\circledR}[16]$. 
This approach would also allow adjusting the performance of the fan with the change of air density.

\subsection{Proof of concept}

A proof of concept study of the smart smoke control concept was given in [7]. In this paper, the Author has presented a case-study of a car park ventilation system, for both traditional (scenarios 1-4) and smart smoke control (scenarios 5-8). The experiment was conducted with ANSYS Fluent ${ }^{\circledR}$, modified with UDF as described above. The solution was carried in double precision $3 \mathrm{D}$ solver with second-order numerical schemes, and URANS (realizable k- $\varepsilon$ ) turbulent flow model. As radiation was not relevant for the analysis, $\mathrm{P} 1$ radiation model was used. An HRR curve representing a growing fire of 3 vehicles was used [17]. The traditional systems had constant capacities from $130000 \mathrm{~m}^{3} / \mathrm{h}$ to $230000 \mathrm{~m}^{3} / \mathrm{h}$, while adaptive solutions were defined with minimum capacity $\left(95000 \mathrm{~m}^{3} / \mathrm{h}\right.$ to $\left.180000 \mathrm{~m}^{3} / \mathrm{h}\right)$ and the rate of change of volumetric flow as a function of temperature.

The analyses have proven, that: (a) smart smoke control system may provide same, or better performance as traditional solution, despite the fact the mechanical properties of system in ambient air were scaled down significantly; (b) it is possible to maintain close to constant pressure and mass flow rate at the outlet, by matching the volumetric exhaust rate to the momentary density; (c) the requirement for ambient air supply were relaxed, and the airflow velocity was close to constant during operation of smart smoke control. The results of the numerical simulations for the smart smoke control system are shown in Table 1, and comparison of some results of numerical simulations are shown in Fig. 4.

\subsection{Improvements in fire safety of buildings}

The smart smoke control system may improve the fire safety in the building, compared to a traditional solution with same mechanical parameters. It is difficult to quantify this increase of safety, but the main benefits that can be identified are:

a) limitation of the temperature of the smoke;

b) extension of the available safe evacuation time;

c) limiting the necessary make-up air supply velocity.

Firstly, as the smart smoke control system does remove more smoke, the average temperature of the smoke in the compartment decreases, proportionally to the increase of exhaust capacity. This means that occupants, firefighters, and the building itself are exposed to smaller thermal stress. It is not possible to quantify precisely the benefits of the lower thermal load, but it is often assumed that every reduction of smoke temperature is valuable. However, the importance of this change may be profound in scenarios, in which the risk of flashover in the compartment is significant (defined as $\Delta \mathrm{T}>550^{\circ} \mathrm{C}$ [18]). Once a flashover occurs in the compartment, the fire changes its behaviour from fuel-bed controlled to a ventilation controlled, and all of the combustible materials are ignited [19]. In smart smoke control, it is possible to remove substantially more air than in traditional solution (e.g. at $\Delta \mathrm{T}=550^{\circ} \mathrm{C}$ smart smoke control may have 3 times the volumetric capacity of a traditional solution), so it may be possible to exhaust more heat from the compartment, efficiently delaying or preventing the flashover. The heat release rate of a fully developed fire is few (or even dozen) times larger, than in case of a local event. Preventing flashover also almost certainly limits the possibility of the spread of fire to other parts of building and enables firefighter response.

Table 1. Results of numerical simulations shown in [7] (C) Elsevier, reproduced with permission)

\begin{tabular}{|c|c|c|c|c|c|c|c|c|}
\hline \multirow{2}{*}{ Time } & \multicolumn{2}{|c|}{ Scenario (5) } & \multicolumn{2}{c|}{ Scenario (6) } & \multicolumn{2}{c|}{ Scenario (7) } & \multicolumn{2}{c|}{ Scenario (8) } \\
\cline { 2 - 9 } & $\begin{array}{c}\text { Average } \\
\text { temperature } \\
\text { of smoke } \\
{[\mathrm{K}]}\end{array}$ & $\begin{array}{c}\text { Volumetric } \\
\text { capacity } \\
{\left[\mathrm{m}^{3} / \mathrm{h}\right]}\end{array}$ & $\begin{array}{c}\text { Average } \\
\text { temperature } \\
\text { of smoke } \\
{[\mathrm{K}]}\end{array}$ & $\begin{array}{c}\text { Volumetric } \\
\text { capacity } \\
{\left[\mathrm{m}^{3} / \mathrm{h}\right]}\end{array}$ & $\begin{array}{c}\text { Average } \\
\text { temperature } \\
\text { of smoke } \\
{[\mathrm{K}]}\end{array}$ & $\begin{array}{c}\text { Volumetric } \\
\text { capacity } \\
{\left[\mathrm{m}^{3} / \mathrm{h}\right]}\end{array}$ & $\begin{array}{c}\text { Average } \\
\text { temperature } \\
\text { of smoke } \\
{[\mathrm{K}]}\end{array}$ & $\begin{array}{c}\text { Volumetric } \\
\text { capacity } \\
{\left[\mathrm{m}^{3} / \mathrm{h}\right]}\end{array}$ \\
\hline $\mathrm{t}=0 \mathrm{~s}$ & 293 & 95616 & 293 & 119916 & 293 & 150012 & 293 & 180212 \\
\hline $\mathrm{t}=300 \mathrm{~s}$ & 322.8 & 101232 & 319.9 & 124704 & 316.9 & 155340 & 313.3 & 187920 \\
\hline $\mathrm{t}=600 \mathrm{~s}$ & 327.7 & 102060 & 324.8 & 125496 & 321.3 & 156204 & 317.8 & 189576 \\
\hline $\mathrm{t}=900 \mathrm{~s}$ & 424.5 & 120672 & 421.1 & 142740 & 400.3 & 173916 & 373.0 & 211572 \\
\hline $\begin{array}{c}\mathrm{t}=1260 \\
\mathrm{~s}\end{array}$ & 499.5 & 134928 & 494.8 & 156096 & 460.0 & 187596 & 421.7 & 231300 \\
\hline $\begin{array}{c}\% \\
\text { vol. } \\
\text { capacity } \\
\text { increase }\end{array}$ & \multicolumn{2}{|c|}{$41.1 \%$} & \multicolumn{2}{|c|}{$30.1 \%$} & & & & \\
\hline
\end{tabular}




\section{Traditional solution}

(1) $V=130000 \mathrm{~m}^{3} / \mathrm{h}$

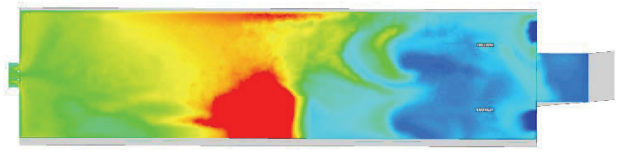

$t=1260 s$

(2) $V=150000 \mathrm{~m}^{3} / \mathrm{h}$

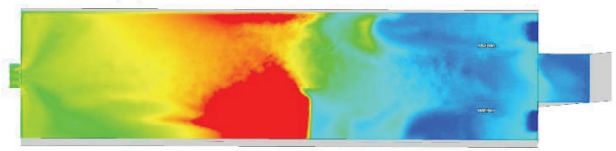

$t=1260 \mathrm{~s}$

(3) $V=180000 \mathrm{~m}^{3} / \mathrm{h}$

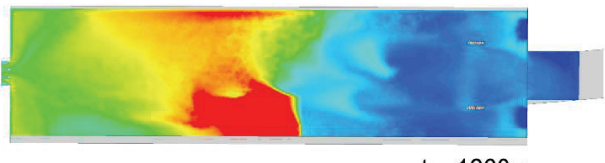

$t=1260 s$

(4) $V=220000 \mathrm{~m}^{3} / \mathrm{h}$

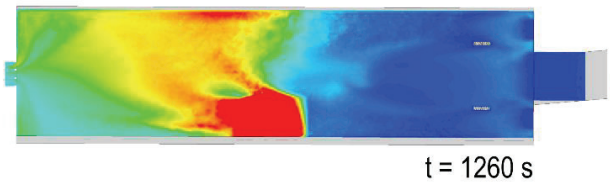

$t=1260 s$
Smart smoke control

(5) $V=95600 \mathrm{~m}^{3} / \mathrm{h}$

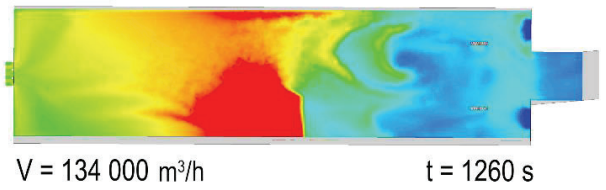

(6) $V=120000 \mathrm{~m}^{3} / \mathrm{h}$

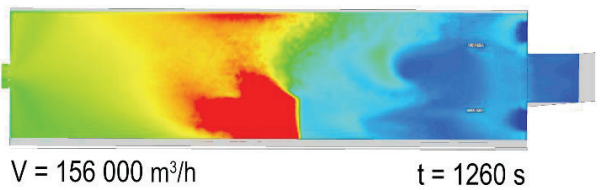

(7) $V=150000 \mathrm{~m}^{3} / \mathrm{h}$

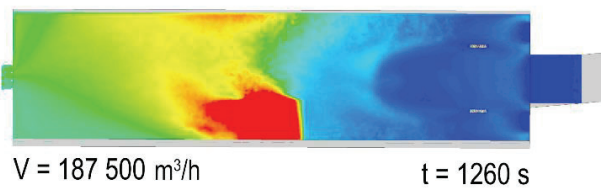

(8) $V=180000 \mathrm{~m}^{3} / \mathrm{h}$

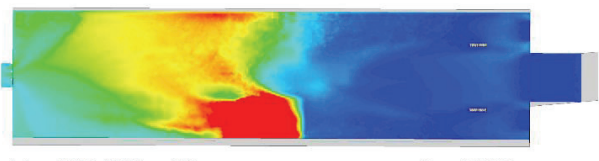

$V=231000 \mathrm{~m}^{3} / \mathrm{h}$

$\mathrm{t}=1260 \mathrm{~s}$

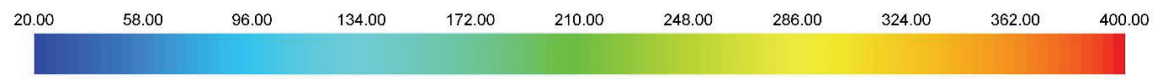

Fig.4. The temperature of smoke $\left(20-400{ }^{\circ} \mathrm{C}\right.$ and more) at the height of $2,00 \mathrm{~m}$ above the floor, for four traditional and four smart smoke control systems, as described in [7]. Systems on the right side did operate at approx. $30 \%$ lower operating pressure, than their traditional counterparts

The second effect is related to the increased removal and dilution of smoke and combustion products from the compartment. With increased exhaust rate, the removal is more efficient, the resulting pollutant concentrations are lower, and ASET time is increased. This has a an effect on the evacuation of occupants, whose safety is the primal goal of the use of smoke control solution. In the case study presented herein the temporal changes in smoke control were not investigated. However, in case of horizontal smoke control systems, the improved exhaust capacity may translate into valuable seconds or minutes of additional evacuation time. The final effect will vary on the case by case basis, but this increase of time may be from $30 \%$ to more than $100 \%$.

Finally, the smart smoke control has a significant effect on the ambient air supply performance, both natural and mechanical. Mechanical air supply delivers a constant amount of air during its operation, while natural air supply does deliver the difference between the mass of air removed from the compartment, and supplied to it with mechanical means. In smart smoke control, the natural air supply should have a constant mass flow (as the system aims to remove the constant mass of air from the compartment), which prevents the reversal of flow direction on the inlet in unfavourable conditions. Consequently, it is also easier to balance the air supply delivered through a mechanical system, as the volume of air to be delivered in both ambient and maximum temperature scenarios is the same (same mass flow), and can be significantly lower than in traditional solutions. Difficulties in air supply (too high velocities at mechanical inlets, reversed flows at natural inlets) can be considered one of leading practical problems with modern smoke control systems, based on the experience of more than 100 systems commissioned by the Author (2010-18) with hot smoke method. 


\subsection{Economic considerations}

The smart smoke control system may have a significant economic impact on the construction costs of the building. The cost of the smart smoke control is higher than of the traditional system with same mechanical parameters at ambient temperature - mainly due to additional sensors, frequency inverters and oversized exhaust fans. However, this increase of costs is offset by the significant change of fire safety in the building - the economic effort to lower temperatures or prolong the tenable conditions in the building with alternative means would be significantly higher than the cost of additional components of smart system. This cost-efficiency of the smart smoke control may be even higher when this solution is used to retrofit existing buildings. Proposed system enables significant change in the safety of the building, by replacing only the terminating device (fan and its automation) of the system, without any changes to the building architecture or shafts.

Secondly, in the design of new buildings, smart smoke control concept may be used to design systems matching the maximum performance of traditional solutions, but requiring smaller shaft spaces, fewer dampers and vanes etc. It must be noted, that in many buildings, the most substantial part of the smoke control solution cost lies not within the mechanical or electrical equipment, but in the leasable area lost to the shafts of the systems. In case of supertall buildings, this may be hundreds or even thousands of $\mathrm{m}^{2}$. Finally, a major saving is possible in large ventilation systems of transportation tunnels. In such construction works, the capacities of smoke control systems are measured in millions of $\mathrm{m}^{3} / \mathrm{h}$, and the size of exhaust ventilators exceeds few metres. Such systems also require high values of operating pressure (often between $2000-3000 \mathrm{~Pa}$ ), which combined with the high capacity of the fans requires ample power supply. With the smart smoke control system, the solution may be designed for much lower operating pressure, which may lead to significant savings in the parameters of exhaust fans, without a sacrifice in their capacity. Also, as the fans are often used for every-day ventilation, limiting the power consumption of these devices will lead to considerable day-to-day savings.

\section{A paradigm shift towards smart smoke control}

Despite the evident benefits of the use of smart smoke control, progression towards the new solution will require significant effort in the areas of:

- development of new design methods;

- experimental verification;

- numerical simulations used in the design process;

- certification and standardization of the solution.

Design of smart smoke control systems will require new methods to include the transient adaptation of the system, in the evaluation of its expected performance. A simplified approach was shown in this paper. However, this does not include a feedback loop between the performance of the system, the fire and environmental conditions within the building. Also, the change of pressure curve of the fan with the change of temperature and density of air must be included in the considerations, as it may impact the overall performance of the smart solution. Finally, the MEP engineers must have clear guidelines on the choice of critical parameters of the system - operating pressures, maximum flow velocities in ambient air, frequencies of the power supply and the overall power demand. This should be provided in the form of guidelines, or even better, as a part of the dedicated software that could calculate all of the complex interactions described above.

For the transition from traditional solutions to smart smoke control, more research is required. Primarily, fullscale experiments in which the change of operating pressure of the system during thermal adaptation can be measured and verified. Also, the performance of auxiliary components, such as ducts, vanes, dampers, silencers etc., should be verified for the new, proposed conditions. Another element that could help form the guidelines for the new solution would be scaled down research, in which the ability of the system to adapt and the consequences of rapid change in volumetric flows would be addressed. Finally, as already pointed out in [7], the behaviour of the new solution in the event of rapid cooling of the smoke (in sprinkler operation or firefighting) remains unknown. This may cause significant changes in pressures within the compartment, as well as changes in flow pattern in the compartment, which has to be further experimentally verified.

As the smart smoke control is applied in practice, it must go through the same numerical verification process with CFD analysis, as traditional solutions. To do this in a correct way, the CFD model used must be able to (a) measure and process the temperature / density of removed smoke; (b) adapt the parameters of boundary conditions, that represent ventilators, based on the processed data. This is already possible with the UDF's created by the Author in ANSYS Fluent ${ }^{\circledR}$ environment. However, this solution must be dissipated among different CFD models and made available to a larger number of design offices. A wider dissipation of this approach may also lead to improvements in the design of smart smoke control systems, as more researchers and designers will participate in the optimization process. The system manufacturers have an essential task in this process by supplying numerical models of their fans and automation. In the foreseeable future, it will be also possible to couple real-time CFD simulations with external, physical control panels, which could process the data from the analysis (e.g. through the external analogue output that simulates a thermocouple) and send back the analogue signal that CFD model may process to adapt the boundary conditions.

Finally, the new smart smoke control system must be compatible with the national law requirements. In Poland, the system should be introduced in so-called $1^{\text {st }}$ system of Assessment and Verification of Constancy of Performance (AVCP), according to [20] and [13]. The smart smoke control systems can be considered formally as part of M/109-23/33 group, "Smoke and heat exhaust ventilation systems - kits" [21]. As no harmonized standard for this solution exists yet, each member country 
can issue national certification for such device. For this purpose, a testing method has to be created, and following performance characteristics should be assessed: operational reliability, the effectiveness of smoke/hot gas extraction, performance parameters under fire conditions and durability [7]. Nevertheless, certification of the kit, all of its components should follow AVCP requirements of relevant standards.

\section{Conclusions}

This paper introduces a new concept of smoke exhaust systems - a dynamic data-driven smoke control system employing real-time temperature measurements and smart algorithms to control the variable volumetric rate of the exhaust. Such solution has a surprisingly profound, positive effect on the performance of smoke exhaust, provides strong economic benefits to the stakeholders and relaxes the requirements for ambient air supply.

The idea of smart smoke control solution was verified with a proof of concept study [7]. However it still requires substantial numerical and experimental confirmation. The potential areas of application are mostly unsprinklered compartments with large fuel loads - such as car parks, offices, shops, theatres and road tunnels. The most promising application is the retrofitting of existing buildings, although the smart smoke control does also have a strong economic impetus for new developments. Estimation of the possible effect on safety and economy of smoke control in these spaces does still require significant research effort.

This paper has also presented the design process of the modern smoke control system. Many of the problems observed with these solutions originate from mixed roles between stakeholders, unnecessary standardization of some aspects of the design and prohibitive, prescriptive laws. To fully enable the change of paradigm towards smart smoke control, this design process must adapt as well - by development of new guidelines, employing newest solutions for design and use of advanced numerical verification of smoke exhaust systems.

\section{References}

1. Węgrzyński, W. \& Sulik, P. Bull. Polish Acad. Sci. Tech. Sci. 64, 719-730 (2016)

2. Thomas, P. H., Hinkley, P. L., Theobald, C. R. \& Simms, D. L. Investigations into the flow of hot gases in roof venting. Fire Research Technical Paper No 7 (1963)

3. Law, M. Fire Saf. J. 10, 197-202 (1986)

4. Morgan, H. P. \& Hansell, G. O. Fire Saf. J. 13, 221-224 (1988)

5. Morgan, H. P. et al. Design methodologies for smoke and heat exhaust ventilation. BR 368 (BRE, 1999)

6. Harrison, R. \& Spearpoint, M. Fire Technol. 43, 301-317 (2007)

7. Węgrzyński, W. Int. J. Heat Mass Transf. 114, 483-500 (2017)

8. Klote, J. H. in SFPE Handbook of Fire
Protection Engineering 1785-1823 (Springer

New York, 2016) doi:10.1007/978-1-4939-2565050

9. NFPA 204 (2015)

10. BSI 7346-4 (2003)

11. Alvarez, A., Meacham, B. J., Dembsey, N. \& Thomas, J. J. Fire Prot. Eng. 23, 249-276 (2013)

12. Tofiło, P., Węgrzyński, W. \& Porowski, R. in 11th Conference on Performance-Based Codes and Fire Safety Design Methods (SFPE, 2016)

13. EN 12101-3:2015-10.

14. Hinkley, P. L. Fire Saf. J. 10, 57-65 (1986)

15. ANSYS. ANSYS Fluent 14.5.0 - Technical

Documentation. (2014)

16. Król, A. \& Król, M. Tunn. Undergr. Sp. Technol. 73, 222-235 (2018)

17. van Oerle, N., Lemaire, A. \& van de Leur, P. in TNO Report No. 1999-CVB-RR1442 (1999)

18. Drysdale, D. D. An Introduction to Fire

Dynamics, 3rd Edition. (Wiley, 2011)

19. Karlsson, B. \& Quintiere, J. G. Enclosure Fire Dynamics. (CRC Press, 2000)

20. UE 305/2011 (2011)

21. UE M/109-23/33 (1996) 